\title{
CARE-GIVER BURDEN IN AUTISM SPECTRUM DISORDER AND SPECIFIC LEARNING DISABILITY- A COMPARATIVE STUDY
}

\section{Psychiatry}

\section{Dr. Dinesh Valvi*}

\section{Dr. Kunal Desai}

\section{Dr. Minakshi N Parikh}

3rd year resident Psychiatry Department, B J Medical College, Civil Hospital, Ahmedabad, Gujarat, India *Corresponding Author

3rd year resident Psychiatry department, B J Medical College, Civil Hospital, Ahmedabad, Gujarat, India

Professor and Head of Department of Psychiatry, BJ Medical College, Civil Hospital, Ahmedabad, Gujarat, India

\section{ABSTRACT}

Aims and objectives: To assess and compare the burden of care in caregivers of patients with Autism Spectrum Disorders and Specific Learning Disability

To assess and compare psychiatric morbidities and caregiver burden in caregivers of patients with Autism Spectrum Disorders and Specific Learning Disability.

To study the burden with relation to socio-demographic characteristics

Material and method: Participants were divided into 2 study group of 40 participants each. Socio-demographic data for both care-givers and patients were collected via a semi-structured interview involving the care-givers of patients who attended the hospital's outpatient department. The care-giver burden will be measured with the Family Burden Interview Schedule (FBIS) and Psychiatric morbidities were measured by General Health Questionnaire-28 (GHQ-28).

Result: The study was carried out to compare the burden of care and psychiatric. In our study socio-demographic characteristics like marital status, family income, and locality showed statistically significant differences between the two groups.

Psychiatric morbidities were statistically significantly higher in caregivers of ASD in all four domains i.e, somatic symptoms, anxiety/insomnia, social dysfunction and depression. We found the burden of care to be statistically significantly higher in the ASD group on all domains except Financial burden, namely Disruption of routine family activities, Disruption of family leisure, Disruption of family interactions, Effect on physical health and Effect on mental health.

conclusion: In our study we have found both burden of care and psychiatric morbidity to be higher in caregivers of ASD children as compared to caregivers of SLD children. This was consistent with our hypothesis that burden of care has strong positive correlation with psychiatric morbidity in caregiver.

\section{KEYWORDS}

\section{INTRODUCTION}

A care giver is defined as the person who fulfils the need of physical and psychological well being of a diseased or disordered individual ${ }^{\mid 11}$ Caring for a child who has a developmental disability can involve significant and prolonged periods of time and energy, completion of physically demanding and unpleasant tasks, and frequent disruption to family routines and activities (Seltzer \& Heller 1997; Shultz \& Quittner 1998). ${ }^{|2| 3|| 4 \mid}$

As a result of these increased care-giving demands, it seems reasonable to assume that parents of children with developmental disabilities are at increased risk for high levels of personal stress. When a parent feels overwhelmed by the stress associated with caring for their child with a disability, there can be negative implications for the child, the parent and the family as a whole. (Moes \& Frea 2000; Bor et al. 2002).

Autism Spectrum Disorders (ASD) include a variety of childhoodonset and lifelong neurodevelopmental disorders with an enduring impact on multiple domains of functioning, characterized by persistent deficits in social communication and social interaction and restricted and repetitive behavior, interests and activities. ${ }^{|6|}$

Even referring to the most conservative prevalence estimates, ASD is among the world's 20 most disabling childhood conditions, with Autistic Disorder accounting for more than 58 DALYs per 100,000 population and other ASDs for 53 DALYs per $100,000 .{ }^{\text {|l| }}$ It has been estimated that more than 2 million people might be affected by ASD in India $^{|s|}$

According to DSM-5 Specific Learning Disability (SLD) is a Neurodevelopmental Disorder that involves marked and persistent difficulties in learning and using one's cultural symbol systems (e.g., alphabetic letters, characters, Arabic numerals) that are required for skilled reading, writing, and arithmetic) ${ }^{[9] .}$ It is one of the most commonly occurring developmental disorders in normal school-going children in India (3\% to 10\% Arun et al,2013) ${ }^{|10|}$

Caregiver burden can lead to negative outcomes for both patients and caregivers and hence addressing this burden can help in reducing the parental stress and lead to better outcomes. Identifying the factors affecting caregiver burden is the first step in addressing it.

ASD and SLD are both certifiable illnesses under the RPWD ACT 2016 and we commonly encounter children with these conditions in our setting. so, considering the paucity of Indian literature pertaining to care giver burden in these two conditions, we thought it would be worthwhile to compare care giver burden in these two disorders.

\section{AIM AND OBJECTIVES}

- To assess and compare the burden of care in caregivers of patients with Autism Spectrum Disorders and Specific Learning Disability.

- To assess and compare psychiatric morbidities and caregiver burden in care givers of patients with Autism Spectrum Disorders and Specific Learning Disability.

- To study the burden with relation to socio-demographic characteristics

\section{MATERIALSAND METHODS:}

The study was conducted on Forty consecutive consenting caregivers of Specific learning disability patients and Forty consecutive consenting caregivers of Autism spectrum disorder patients approaching the outpatient section of the department of Psychiatry, BJ Medical College \& Civil Hospital, Ahmedabad

This study uses Pollak and Perlick (1991) method to identify primary caregiver.

According to this method-

A primary caregiver is one who satisfies 3 or more of the following 5 criteria:

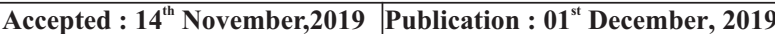


1. Spouse, parent or spouse equivalent

2. Most frequent contact with patients

3. Supports patient financially

4. Most frequent collateral participant in the patient's treatment

5. Is the person contacted in case of an emergency. ${ }^{[11]}$

\section{SUBJECT SELECTION:}

Inclusion criteria: Subjects meeting the following criteria were included

1. Caregivers of children who were certified as having Autism spectrum disorders or Specific learning disability.

2. Caregivers satisfying the requirements of Pollak and Perlick criteria.

Exclusion criteria: subjects were excluded from the study if-

1. They were unwilling to participate in the study.

2. Care givers not satisfying the requirements of Pollak and Perlick criteria

\section{METHODOLOGY:}

The study was approved by the institutional Ethics Committee, BJ Medical College and Civil hospital Ahmedabad.

Participants were divided into 2 study groups of 40 participants each Written informed consent was obtained from all caregivers who participated in the study.

Socio-demographic data of caregivers were collected via a semistructured proforma The caregiver burden was measured with the Family Burden Interview Schedule (FBIS) and the presence/absence of psychiatric morbidity was assessed using the General Health Questionnaire-28(GHQ-28)

\section{INSTRUMENTS}

1.A semi-structured proforma which was used for recording sociodemographic data, comprised of information about age, sex, education, marital status, occupation, family income, locality.

Additional clinical information about the diagnosis of the patient (whether SLD or ASD) was included here.

2. Family Burden Interview Schedule (FBIS) developed by Pai and Kapur (1981) is a semi-structured interview which consists of 6 domains and 24 items.

Each item is scored as 0,1 or 2 depending on the severity. At the end, subjective burden is also recorded and even here, severity is rated as 0,1 or 2 .

The validity and reliability of the scale have been shown to be satisfactory. The inter-rater reliability for all items was reported to be more than $0.78 .^{[12]}$

Relevant permissions were sought from Cambridge University Press for the use of this scale in our study.

3. General Health Questionnaire-28 (GHQ-28) was developed by Goldberg and Hillier in 1979. It consists of 28 questions.

For each item, four possible answers are available (0-not at all, 0-no more than usual, 1-rather more than usual, 2- much more than usual) Cut off score 4 or more is indicative of psychiatric morbidity ${ }^{|13|}$

Validity and reliability of the scale have been shown to be satisfactory. Test-retest reliability has been reported to be high $(0.78$ to 0.9$)$ (Robinson and Price 1982) ${ }^{[14]}$ and inter-rater and intra-rater reliability have both been shown to be excellent (Cronbach's $\alpha$ 0.9-0.95) (Failde and Ramos 2000) ${ }^{[15]}$.

\section{ANALYSIS}

Data were entered into Microsoft Excel data sheets, Chi-square, twoway ANOVA test and Mann-Whitney U test used in further analysis.

P-value (Probability that the result is true) of $<0.05$ was considered as statistically significant after assuming all the rules of statistical tests
RESULTS

Table 1. Socio-demographic characteristics of study participants (N=80)

\begin{tabular}{|c|c|c|c|}
\hline Variables & $\begin{array}{l}\text { SLD } \\
(\mathrm{n}=40)\end{array}$ & $\begin{array}{l}\text { ASD } \\
(n=40)\end{array}$ & $\begin{array}{l}P \\
\text { value** }\end{array}$ \\
\hline $\begin{array}{l}\text { Age (in years) } \\
\geq 38 \\
<38\end{array}$ & $\begin{array}{l}21(52.5) \\
19(47.5)\end{array}$ & $\begin{array}{l}19(47.5) \\
21(52.5)\end{array}$ & 0.8 \\
\hline \begin{tabular}{|l|} 
Gender \\
Male \\
Female \\
\end{tabular} & $\begin{array}{l}15(37.5) \\
25(62.5)\end{array}$ & $\begin{array}{l}14(35.0) \\
26(65.0)\end{array}$ & 1.0 \\
\hline \begin{tabular}{|l|} 
Marital Status \\
Single \\
Couple \\
\end{tabular} & $\begin{array}{l}2(5.0) \\
38(95.0) \\
\end{array}$ & \begin{tabular}{|l}
$2(5.0)$ \\
$38(95.0)$ \\
\end{tabular} & 0.6 \\
\hline $\begin{array}{l}\text { Occupation } \\
\text { Clerical worker and above Skilled } \\
\text { worker and below }\end{array}$ & $\begin{array}{l}19(47.5) \\
21(52.5)\end{array}$ & $\begin{array}{l}18(45) \\
21(55)\end{array}$ & 0.8 \\
\hline \begin{tabular}{|l} 
Education \\
Graduation and more \\
Intermediate \\
Minimal \\
\end{tabular} & $\begin{array}{l}24(60.0) \\
14(35.0) \\
2(5.0) \\
\end{array}$ & $\begin{array}{l}18(45.0) \\
18(45.0) \\
4(10.0) \\
\end{array}$ & 0.3 \\
\hline $\begin{array}{l}\text { Family Income } \\
\geq 19000 \\
<19000\end{array}$ & $\begin{array}{l}38(95.0) \\
2(5.0)\end{array}$ & $\begin{array}{l}23(57.5) \\
17(42.5)\end{array}$ & $<0.0001$ \\
\hline \begin{tabular}{|l|} 
Religion \\
Hindu \\
Others \\
\end{tabular} & $\begin{array}{l}38(95.0) \\
2(5.0)\end{array}$ & $\begin{array}{l}31(77.5) \\
9(22.5)\end{array}$ & $<0.05$ \\
\hline \begin{tabular}{|l|} 
Family Type \\
Nuclear \\
Joint
\end{tabular} & $\begin{array}{l}30(75.0) \\
10(25.0)\end{array}$ & $\begin{array}{l}28(70.0) \\
12(30.0)\end{array}$ & 0.8 \\
\hline \begin{tabular}{|l|} 
Locality \\
Rural \\
Urban \\
\end{tabular} & $\begin{array}{l}5(12.5) \\
35(87.5) \\
\end{array}$ & $\begin{array}{l}11(27.5) \\
29(72.5)\end{array}$ & 0.16 \\
\hline
\end{tabular}

Table 1 shows the socio-demographic characteristics of the sample population. Most of the socio-demographic variables are comparable in both groups. In case of family income, caregivers with ASD have lower income than caregivers of SLD and the difference was found to be statistically significant. The caregivers of Hindu religion more in SLD group as compare ASD group and We are of the opinion that this finding reflects the distribution in the general population at large and the difference was found to be statistically significant.

Table 2. Comparison of sub scales and total score of GHQ in SLD Group and ASD Group care givers

\begin{tabular}{|c|c|c|c|}
\hline \multirow[t]{2}{*}{ Variable } & \multicolumn{2}{|l|}{ Mean \pm SD } & \multirow[t]{2}{*}{ Pvalue* } \\
\hline & $\begin{array}{l}\text { SLD Group } \\
(n=40)\end{array}$ & $\begin{array}{l}\text { ASD Group } \\
(n=40)\end{array}$ & \\
\hline \begin{tabular}{|l|} 
Somatic Symptoms \\
\end{tabular} & $0.4 \pm 1.0$ & $1.3 \pm 1.9$ & $<0.001$ \\
\hline \begin{tabular}{|l|} 
Anxiety/Insomnia \\
\end{tabular} & $0.6 \pm 1.5$ & $1.9 \pm 2.3$ & $<0.001$ \\
\hline Social Dysfunction & $0.5 \pm 1.2$ & $1.6 \pm 2.4$ & $<0.001$ \\
\hline Severe Depression & $0.2 \pm 0.6$ & $1.3 \pm 1.8$ & $<0.001$ \\
\hline Total Score of GHQ & $1.7 \pm 4.0$ & $6.0 \pm 7.8$ & $<0.001$ \\
\hline
\end{tabular}

* - Mann-Whitney U test

Table 2 is a comparison of subscales and total scores of GHQ in the SLD and ASD caregiver groups. The table shows that the burden of care was statistically significantly higher in the ASD group on all domains $(\mathrm{p}<0.05)$.

Table 3. Care giver and Psychiatric morbidity based on GHQ-28 score 4 or more

\begin{tabular}{|l|l|l|l|}
\hline GHQ Total & SLD & ASD & P value \\
\hline$<4$ & 34 & 22 & 0.0073 \\
\hline$\geq 4$ & 6 & 18 & \\
\hline
\end{tabular}

In our study, we found that 18 caregivers with ASD group screened positive for psychiatric morbidity as compared to 6 from the SLD group and this difference was found to be statistically significant.

Table 4. Comparison of sub scales and total score of FBIS in SLD Group and ASD Group care givers

\begin{tabular}{|c|c|c|c|}
\hline \multirow[t]{2}{*}{ Variable } & \multicolumn{2}{|l|}{ Mean \pm SD } & \multirow{2}{*}{$\begin{array}{l}\text { P- } \\
\text { value* }\end{array}$} \\
\hline & $\begin{array}{l}\text { SLD Group } \\
(\mathrm{n}=40)\end{array}$ & $\begin{array}{l}\text { ASD Group } \\
(n=40)\end{array}$ & \\
\hline
\end{tabular}




\begin{tabular}{|l|l|l|l|}
\hline Financial Burden & $0.7 \pm 1.2$ & $1.3 \pm 1.4$ & $>0.05$ \\
\hline $\begin{array}{l}\text { Disruption of routine family } \\
\text { activities }\end{array}$ & $0.8 \pm 0.9$ & $3.7 \pm 1.8$ & $<0.001$ \\
\hline Disruption of family leisure & $0.4 \pm 0.8$ & $1.5 \pm 1.4$ & $<0.001$ \\
\hline $\begin{array}{l}\text { Disruption of family } \\
\text { interactions }\end{array}$ & $0.4 \pm 0.9$ & $1.1 \pm 1.0$ & $<0.001$ \\
\hline Effect on physical health & $0.1 \pm 0.3$ & $0.5 \pm 0.7$ & $<0.001$ \\
\hline Effect on mental health & $0.9 \pm 1.2$ & $1.7 \pm 1.4$ & $<0.001$ \\
\hline Total Score & $3.7 \pm 5.0$ & $10.7 \pm 7.0$ & $<0.001$ \\
\hline
\end{tabular}

*Mann-Whitney U test

Table 4. is a comparison of subscales and total scores of FBIS in the SLD and ASD caregiver groups. The table shows that burden of care was statistically significantly higher in the ASD group on all domains $(p<0.05)$ except "financial burden", where the burden was statistically not significantly higher in the ASD group ( $p>0.05)$.

Table 5. Comparison of GHQ grand total and FBIS grand total according to marital status between two groups.

\begin{tabular}{|l|l|l|l|l|}
\hline \multirow{3}{*}{ Marital status } & GHQ total & \multicolumn{3}{|l|}{ FBIS grand total } \\
\cline { 2 - 5 } & SLD & ASD & SLD & ASD \\
\cline { 2 - 5 } & Mean & Mean & Mean & Mean \\
\hline Single & 13.50 & 17.50 & 15.50 & 19.00 \\
\hline Married & 1.05 & 5.42 & 3.08 & 10.24 \\
\hline p-value & 0.003 & 0.531 & & \\
\hline
\end{tabular}

There was a statistically significant difference found in mean GHQ score between the two groups with respect to marital status. In both SLD and ASD groups, caregivers who were single were found to have significantly higher mean GHQ total scores as compared to caregivers who were married, and this difference was found to be statistically significant

There was no statistically significant difference found in mean FBIS score between the two groups with respect to marital status.

Table 6. Comparison of GHQ grand total and FBIS grand total according to Family income between two groups.

\begin{tabular}{|l|l|l|l|l|}
\hline \multirow{2}{*}{$\begin{array}{l}\text { Family } \\
\text { income }\end{array}$} & GHQ total & \multicolumn{3}{|l|}{ FBIS grand total } \\
\cline { 2 - 5 } & SLD & ASD & SLD & ASD \\
\cline { 2 - 5 } & Mean & Mean & Mean & Mean \\
\hline$>19000$ & 1.05 & 2.91 & 3.08 & 10.19 \\
\hline$<19000$ & 13.50 & 10.24 & 15.50 & 12.33 \\
\hline P Value & $<0.001$ & 0.178 & & \\
\hline
\end{tabular}

There was a statistically significant difference found in mean GHQ score between the two groups with respect to Family Income (with caregivers earning $<19000$ exhibiting significantly higher GHQ score in both SLD and ASD groups)

There was no statistically significant difference found in mean FBIS score between the two groups with respect to Family Income.

Table 7. Comparison of GHQ grand total and FBIS grand total according to family type between two groups.

\begin{tabular}{|l|l|l|l|l|}
\hline \multirow{3}{*}{ Locality } & \multicolumn{3}{|l|}{ GHQ total } & FBIS grand total \\
\cline { 2 - 5 } & SLD & ASD & SLD & ASD \\
\cline { 2 - 5 } & Mean & Mean & Mean & Mean \\
\hline Rural & 3.20 & 8.27 & 7.80 & 14.18 \\
\hline Urban & 1.46 & 5.17 & 3.11 & 9.34 \\
\hline P Value & $<0.001$ & 0.953 & & \\
\hline
\end{tabular}

There was a statistically significant difference found in mean GHQ score between the two groups with respect to Locality (with caregivers residing in rural areas exhibiting higher mean score in both SLD and ASD groups)

There was no statistically significant difference found in mean FBIS score between the two groups with respect to Locality

\section{DISCUSSION}

I. Distribution of Socio-demographic characteristics and correlation with Care giver burden

1. Mean age: The present study found that the mean age of participants among the ASD group was lower than the SLD group. Mean age in the ASD group was 36.6 years and almost more than half of the participants were below 38 years. However, the difference was not statistically significant. Despite this, the difference may be explained by the fact that children with ASD are usually diagnosed earlier than children with SLD due to their behavioral problems. This finding is comparable with the study done by AL-Dujaili AH et al ${ }^{[16]}$ and Pandey $\mathrm{S}$ et $\mathrm{al}^{[17]}$ while finding a similar study done by Shivers $\mathrm{CM}$ et al ${ }^{[18]}$ had a contradictory finding. There was no statistically significant difference found in mean GHQ score and in mean FBIS score between the two groups with respect to age.

\section{Sex:}

The present study found the female: male ratio to be 1:0.6 and 1:0.5 in SLD \& ASD group respectively. This observation is consistent with the studies done by AL-Dujaili AH et al ${ }^{[16]}$ and Nikmat AW et al ${ }^{[19]}$ where the majority of caregivers were female. There was no statistically significant difference found in mean GHQ score and in mean FBIS score between the two groups with respect to sex.

\section{Marital status:}

In our study, the Specific Learning Disability group comprised of 5.0\% unmarried participants and $95.0 \%$ married participants and the Autism Spectrum Disorder group also comprised of $5.0 \%$ unmarried and $95.0 \%$ married participants. The difference was not statistically significant. This above finding is consistent with Yuen et al ${ }^{120 \mid}$ who found that $(90 \%)$ of the caregivers with autistic children were married. With a $P$ value of 0.003 , There was a statistically significant difference found in mean GHQ score between the two groups with respect to marital status. In both SLD and ASD groups, caregivers who were single were found to have significantly higher mean GHQ total scores as compared to caregivers who were married, and this difference was found to be statistically significant.

There was no statistically significant difference found in mean FBIS score between the two groups with respect to marital status.

\section{Occupation:}

The difference was not statistically significant. There was no statistically significant difference found in mean GHQ score and in mean FBIS score between the two groups with respect to occupation.

and above findings are consistent with Nikmat AW et al who did not find any association between occupation and caregiver burden ${ }^{[19 \mid}$

\section{Education:}

The difference was not statistically significant. In our sample, $3 / 5^{\text {th }}$ participants in SLD group and more than $2 / 5^{\text {th }}$ participants in ASD group were educated up to graduation \& more. This finding is comparable with the study done by Shivers $\mathrm{CM}$ et al ${ }^{[18]}$. There was no statistically significant difference found in mean GHQ score and in mean FBIS score between the two groups with respect to Education

\section{Family income:}

In our study, $95.0 \%$ participant's income was $\geq 19000$ Rs and $5.0 \%$ participant's income was $<19000$ Rs in the Specific Learning Disability group and $57.5 \%$ participant's income was $\geq 19000$ Rs and $42.5 \%$ participant's income was $<19000$ Rs in the Autism Spectrum Disorder group. In case of family income, caregivers with ASD were found to have lower income than caregivers of SLD and the difference was found to be statistically significant $(P-v a l u e<0.0001)$. With a P-value of $<\mathbf{0 . 0 0 1}$, there was a statistically significant difference found in mean GHQ score between the two groups with respect to Family Income (with caregivers earning $<19000$ exhibiting significantly higher GHQ score in SLD and ASD group). The findings of Nikmat AW et al ${ }^{[19]}$ were contradictory to our observations.

There was no statistically significant difference found in mean FBIS score between the two groups with respect to Family Income

\section{Religion:}

In the present study $95.0 \%$ participants were Hindu and $5.0 \%$ participants were from other religions in Specific Learning Disability group and $77.5 \%$ participant were Hindu and $22.5 \%$ participants were from other religions from Autism Spectrum Disorder group. The difference was statistically significant $(\mathbf{P}$-value $<\mathbf{0 . 0 5})$. We are of the opinion that this finding reflects the distribution in the general population at large. There was no statistically significant difference found in mean GHQ score in mean FBIS score between the two groups with respect to Religion. 
8. Family type: The present study shows that $75.0 \%$ participants were residing in a nuclear family and $25.0 \%$ belonged to a joint family in Specific Learning Disability group and $70.0 \%$ participants were residing in a nuclear family and $30.0 \%$ belonged to a joint family in Autism Spectrum Disorder group. The difference was not statistically significant. This result is consistent with a previous study done by Sahu et $\mathrm{al}^{[211}$ who found $63.3 \%$ caregivers living in a nuclear family. There was no statistically significant difference found in mean GHQ score in and mean FBIS score between the two groups with respect to Family type.

\section{Locality:}

In our study $12.5 \%$ participants were residing in a rural area and $87.5 \%$ were residing in an urban area in Specific Learning Disability group and $27.5 \%$ participants were residing in a rural area and $72.5 \%$ were residing in an urban area in Autism Spectrum Disorder group. The difference was not statistically significant. However, in our study, caregivers mostly came from urban localities, which is a consistent finding with a previous study done by Sahu et al ${ }^{1211}$. The urban location of our centre coupled with the observation that most of our rural clientele come from low-income households and find it financially challenging to commute to our centre for help, could possibly explain the above finding. With a $\mathbf{P}$ value $<\mathbf{0 . 0 0 1}$, There was statistically significant difference found in mean GHQ score between the two groups with respect to Locality (with care giver residing rural area exhibiting higher mean score in SLD and ASD group).

There was no statistically significant difference found in mean FBIS score between the two groups with respect to Locality

\section{Comparison of Subscales and total scores of GHQ in the SLD and ASD Caregiver Groups.}

comparison of subscales and total scores of GHQ in the SLD and ASD caregiver groups. The table shows that the burden of care was statistically significantly higher in the ASD group on all domains $(\mathbf{p}<0.05)$.

This finding is in line with the results on the FBIS subscale "effect on mental health", which show marginally higher scores in caregivers in the ASD group. This finding is correlated with the study done by Black DW et al ${ }^{\mid 22]}$, Jayantkumar C et al. ${ }^{|23|}$

\section{Caregiver and Psychiatric morbidity based on GHQ-28 score 4} or more

In our comparison we found that 18 caregivers with ASD group screened positive for psychiatric morbidity as compared to 6 from SLD group and this difference was found to be statistically significant.

\section{Comparison of Sub scales and total scores of FBIS in the SLD and ASD Care giver Groups.}

Burden of care was statistically significantly higher in the ASD group on all domains $(p<0.05)$ except "financial burden", where burden was statistically not significantly higher in the ASD group $(\mathrm{p}>0.05)$.

The FBIS questionnaires uncovered considerable burden of care among caregivers in both disorders. The mean total burden score for ASD was statistically significantly higher than that for SLD. The findings are comparable to those of Veltro $\mathrm{F}$ et al ${ }^{|24|}$ and Thomas et al ${ }^{|25|}$

In comparisons II, III and IV mentioned above, GHQ scores (total and mean), psychiatric morbidity, and FBIS scores were statistically significantly higher in caregivers of ASD group. The earlier diagnosis and higher incidence of behavioral problems in children with ASD as compared to children with SLD could be a possible explanation for the above findings.

\section{SUMMARY}

The study was carried out to compare the burden of care and psychiatric morbidity among care givers of patients with SLD and ASD. It was a cross sectional study. In our study socio-demographic characteristics like marital status, family income, and locality showed statistically significant differences between the two groups.

Psychiatric morbidities were statistically significantly higher in caregivers of ASD in all four domains i.e. somatic symptoms, anxiety/insomnia, social dysfunction and depression. We found the burden of care to be statistically significantly higher in the ASD group on all domains except Financial burden, namely Disruption of routine family activities, Disruption of family leisure, Disruption of family interactions, Effect on physical health and Effect on mental health.

\section{CONCLUSION}

In our study we have found both burden of care and psychiatric morbidity to be higher in care givers of ASD children as compared to caregivers of SLD children. This was consistent with our hypothesis that burden of care has strong positive correlation with psychiatric morbidity in caregiver. In ASD, the of nature of illness itself is such that it impairs the child in multiple domains, and places higher demands on the caregivers. We have also observed that in the ASD group, caregivers were younger than in the SLD group - and younger caregivers might not have coping skills better than older caregivers due to various reasons like being less settled in their careers and greater occupational demands, less parenting experience and lesser support networks. The above reasons could be possibly explaining the higher caregiver burden observed in the ASD caregiver group in our study.

We hope that out of this study contributes to a better understanding of caregiver burden in SLD and ASD, which are two of the disorders increasingly coming into focus in our society, as a result of increasing awareness and acceptance in society and also their status as certifiable illnesses in the RPWD act, 2016. A better understanding of caregiver burden could contribute to interventions which account for this burden and include strategies to manage it, potentially leading to better outcomes for the entire family unit.

\section{LIMITATIONS}

- Sample size of the study was average.

- Relationship between nature and severity of Autism spectrum disorder and Specific learning disability symptoms and degree of burden of care was not examined.

- In our study duration of illness was not counted.

- The study was conducted at a single center which may not represent the community.

- Emotional climate and interaction patterns within the family, and the social support perceived by both patients and relatives could not be assessed

\section{FUTURE RECOMMENDATIONS}

- A further study with a large sample size, preferably including community sample, is essential to confirm the present findings.

- There is a need to examine the relationship between the degree of psycho pathology and burden, and to evaluate the mental state of caregivers with standardized instruments

\section{REFERENCES}

. Swain S, Behura S, Dash M. A comparative study of family burden and quality of life between caregivers of schizophrenia and dementia patients. International Journal of Community Medicine and Public Health. 2017;4(6):2021

2. Aschbrenner, K. A., Greenberg, J. S., Allen, S. M., \& Seltzer, M. M. (2010). Subjective burden and personal gains among older parents of adults with serious mental illness. Psychiatric services (Washington, D.C.),61(6), 605-611 doi:10.1176/ ps. 2010. 61.6.605

3. Hayden, M.F., \& Heller, T. (1997). Support, problem-solving/coping ability, and personal burden of younger and older caregivers of adults with mental retardation. Mental retardation, 35 5, 364-72

4. Shultz R. \& Quittner A.L. (1998) Caregiving for children and adults with chronic conditions: introduction to the special issue. Health Psychology 17,107-

Moes D.R. \& Frea W.D. (2000) Using family context to inform prevention planning for the treatment of a child with autism. Journal of Positive Behaviour Interventions 2, 40-6. disorders. 5thed Arlington, VA: American Psychiatric Association 2013

7. Baxter AJ, Brugha TS, Erskine HE, Scheurer RW, Vos T, Scott JG. The epidemiology and global burden of autism spectrum disorders. Psychol Med 2015; 45(3): 601-13 [http://dx.doi.org/10.1017/S003329171400172X] [PMID: 25108395]

8. Krishnamurthy V. A clinical experience of autism in India. J Dev Behav Pediat 2008;29:331-3.

9. Sadock B, Sadock V, Ruiz P. Kaplan \& Sadock's comprehensive textbook of psychiatry. 10th ed. 2017 (page no. 3521)

10. Arun P, Chavan BS, Bhargava R, Sharma A, Kaur J, Prevalence of specific developmental disorder of scholastic skill in school students in Chandigarh, India. Indian J Med Res 2013;138:89-9

11. Pollack CP, Perlick D (1991) Sleep problems and institutionalization of the elderly. Journal of Geriatric Psychiatry and Neurology, 4:204-210

12. Pai S. and Kapoor RL. (1982) Impact of treatment intervention on the relationship between dimensions of clinical psychopathology, social dysfunction and burden on the family of psychiatric patients. Psychological Medicine, 12, 651-658

13. Goldberg DP, Hiller VF. (1979) A Scaled version of the General Health Questionnaire Psychological Medicine. February; 9(1):139-145.

Robinson R, Price T (1982) Stroke 13:635.

15. Failde I Ramos R (2000) Europ J Epidem 16:311

16. Al-Dujaili AH, Al-Mossawy DAJ. Psychosocial burden among caregivers of children with autism spectrum disorder in Najaf province. Curr Pediatr Res 2017; 21 (2):272282

7. Pandey S, Sharma C. Perceived Burden in Caregivers of Children with Autism Spectrum Disorder. J Nepal Health Res Counc 2018 Apr-Jun; 16(39): 184-9.

18. Shivers CM, Libbie SN, Lee GK. Needs and Experiences of Family Caregivers of 
Individuals With Autism Spectrum Disorders Across the Lifespan. Journal of Policy and Practice in Intellectual Disabilities 2019;16(1):21-29.

19. Nikmat AW, Mahadir A, Lai ON, et al. Stress and psychological well-being among parents of children with autism spectrum disorder. ASEAN J Psychiatry 2008; 9:64-72.

20. Yuen C, Wai C. Quality of life of parents who have children with disabilities. Hong Kong Journal of Occupational Therapy 2003; 13: 19-24.

21. Sahu, Anamika et al. "Perception of Families of Children with Specific Learning Disorder: An Exploratory Study.” Indian journal of psychological medicine vol. 40,5 (2018): 406-413. doi:10.4103/IJPSYM.IJPSYM_148 18

22. Black DW, Gaffney G, Schlosser S, Gabel J. The impact of obsessive-compulsive disorder on the family: preliminary findings. J Nerv Ment Dis. 1998; 186(7): 440-442.

23. Jayakumar C, Jagadeesan K, Verma AN. Caregiver's burden: a comparison between obsessive compulsive disorder and schizophrenia. Indian J Psychiatry. 2002; 44(4): obsessive co 3372 .

24. Veltro F, Maglian L, Lobrace S. Burden on the relatives of patients with schizophrenia versus neurotic disorders: A pilot study. Soc Psychiat Epidemiol. 1994; 29(2): 66-70.

25. Thomas JK, Sureshkumar PN, Verma AN, Sinha VK, Andrade C. Psychosocial dysfunction and family burden in schizophrenia and obsessive-compulsive disorder. Indian J Psychiatry. 2004; 46(3): 238-2. 